\title{
A stress response pathway in mice upregulates somatostatin level and transcription in pancreatic delta cells through Gs and $\beta$-arrestin 1
}

\author{
Hong-Mei Wang • Jun-Hong Dong • Qing Li • Qiaoxia Hu • Shang-Lei Ning • \\ Wenshuai Zheng $\cdot$ Min Cui $\cdot$ Tian-Sheng Chen $\cdot$ Xin Xie • Jin-Peng Sun $•$ Xiao Yu
}

Received: 27 January 2014 / Accepted: 16 May 2014 / Published online: 20 June 2014

(C) Springer-Verlag Berlin Heidelberg 2014

\begin{abstract}
Aims/hypothesis Somatostatin secretion from islet delta cells plays an important role in regulating islet function and is tightly controlled by environmental changes. Activation of the adrenergic system promoted somatostatin secretion from islet delta cells; however, the role of the adrenergic system in regulating
\end{abstract}

Hong-Mei Wang, Jun-Hong Dong and Qing Li contributed equally to this work.

Electronic supplementary material The online version of this article (doi:10.1007/s00125-014-3290-0) contains peer-reviewed but unedited supplementary material, which is available to authorised users.

H.-M. Wang · J.-H. Dong $\cdot$ Q. Li $\cdot$ W. Zheng $\cdot$ M. Cui $\cdot$ X. Yu $(\bowtie)$

Key Laboratory Experimental Teratology of the Ministry of Education and Department of Physiology, Shandong University

School of Medicine, 44 Wenhua Xi Road, Jinan,

Shandong 250012, China

e-mail: yuxiao@sdu.edu.cn

J.-H. Dong $\cdot$ Q. Hu $\cdot$ J.-P. Sun $(\bowtie)$

Department of Molecular Biology and Biochemistry, Shandong

University School of Medicine, 44 Wenhua Xi Road, Jinan,

Shandong 250012, China

e-mail: sunjinpeng@sdu.edu.cn

J.-H. Dong

Weifang Medical University, Weifang, Shandong, China

Q. $\mathrm{Hu} \cdot$ J.-P. Sun

Key Laboratory Protein Science of Chronic Degenerative Diseases in Universities of Shandong, Shandong, China

S.-L. Ning $\cdot X$. Yu

Qilu Hospital, Shandong University, Jinan, Shandong, China

T.-S. Chen

Key Laboratory of Freshwater Animal Breeding, Ministry of Agriculture, College of Fisheries, Huazhong Agricultural University, Wuhan, Hubei, China

X. Xie

Shanghai Institute of Materia Medica, Shanghai, China somatostatin content and transcription has not been defined. An imbalance between the somatostatin content and its secretion may cause dysfunctions in the islet delta cells. We have investigated the role of the adrenergic system in the modulation of somatostatin content and transcription in pancreatic delta cells and the detailed underlying mechanisms of this regulation. Methods The stress hormone adrenaline (epinephrine), specific adrenergic agonists or specific adrenergic antagonists were applied to islets from either wild-type or specific adrenergic receptor knockout mice and pancreatic delta cell lines to investigate their effects on somatostatin content and transcription. The GloSensor assay, quantitative real-time PCR, western blots and the dual luciferase assay were used to monitor the cAMP level, somatostatin expression, activations of kinases and transcriptional factors. Arrbl knockout mice, specific Creb or Pax6 mutations and specific kinase inhibitors were used to dissect the signalling pathway.

Results Adrenaline and isoprenaline increased somatostatin content and transcription through the activation of $\beta 1-/ \beta 2$ adrenergic receptors ( $\beta 1-/ \beta 2 \mathrm{ARs})$. The somatostatin content in $\beta 1 A R^{-1-} / \beta 2 A R^{-/-}$(Adrb1/Adrb2 knockout) mice was 50\% lower than in $\beta 1 A R^{+/+} / \beta 2 A R^{+/+}$mice. Two parallel signalling pathways, Gs-cAMP-protein kinase A (PKA)-cAMP response element binding protein (CREB) and $\beta$-arrestin $1-$ extracellular signal-related kinase (ERK)-paired box protein 6 (PAX6), cooperatively regulated isoprenaline-induced somatostatin transcription.

Conclusions/interpretation A stress pathway increased somatostatin content and transcription through $\beta$-adrenergic agonism. $\beta$-Arrestin1, ERK and PAX6 are important pancreatic delta cell regulators in addition to cAMP, PKA and CREB. Dysfunction of $\beta$-adrenergic agonism may impair pancreatic delta cell function.

Keywords Adrenergic receptors - $\beta$-Arrestin 1 - CREB . Pancreatic delta cell · PAX6 · PDX1 - Somatostatin · Stress 


$\begin{array}{ll}\begin{array}{l}\text { Abbreviations } \\ \beta 1 \mathrm{AR}, \beta 2 \mathrm{AR},\end{array} & \beta 1-, \beta 2-, \beta 3 \text {-adrenergic receptor } \\ \beta 3 \mathrm{AR} & \\ \text { CREB } & \begin{array}{l}\text { cAMP response element binding } \\ \text { protein }\end{array} \\ \text { ERK } & \text { Extracellular signal-related kinase } \\ \text { GPCR } & \begin{array}{l}\text { G-protein-coupled receptor } \\ \text { PAX }\end{array} \\ \text { PDX1 } & \text { Paired box protein } \\ \text { PKA } & \text { Pancreatic and duodenal homeobox 1 } \\ & \text { Protein kinase A }\end{array}$

\section{Introduction}

The islets of Langerhans contain multiple types of endocrine cells, which produce glucagon (alpha cells), insulin (beta cells), somatostatin (delta cells), pancreatic polypeptide (PP cells) and ghrelin (epsilon cells). The crosstalk between these cells forms a finely tuned network that controls hormone release and maintains normal growth and survival of the islets. For example, somatostatin secreted from the islet delta cells regulates the responses of the islet beta and alpha cells to physiological changes $[1,2]$. An increase in the circulating glucose concentration triggers the release of somatostatin from the pancreatic delta cells, which exerts inhibitory effects on both insulin secretion from the beta cells and glucagon secretion from the alpha cells $[1,3,4]$. While somatostatin limits the insulin response to glucose in an inhibitory circuit, it is essential for the effect of glucose in decreasing glucagon secretion from alpha cells [1]. Therefore, somatostatin is an important intra-islet-circuit hormone. An inappropriate somatostatin level may lead to disorders of islet function.

In the pancreatic delta cells, somatostatin is tightly controlled to react to environmental changes. The adrenergic system, which is activated by either adrenaline (epinephrine) released from the adrenal medulla or noradrenaline (norepinephrine) released from the sympathetic nerves, is one of the most important regulators of delta cells and adapts islets to increased psychological or physical demands [5-8]. Previous studies have demonstrated that activation of the adrenergic system in pancreatic delta cells promotes somatostatin secretion, mainly through $\beta$-adrenergic agonism $[6,7$, 9]. However, the effects of activating the adrenergic system on the somatostatin level in pancreatic delta cells are not known.

Here, we demonstrate that the activation of the adrenergic system promotes an increase in the somatostatin level and transcription. Mechanistically, both the Gs-cAMP response element binding protein (CREB) and the $\beta$-arrestin 1-paired box protein 6 (PAX6) pathways mediate the adrenergic effects
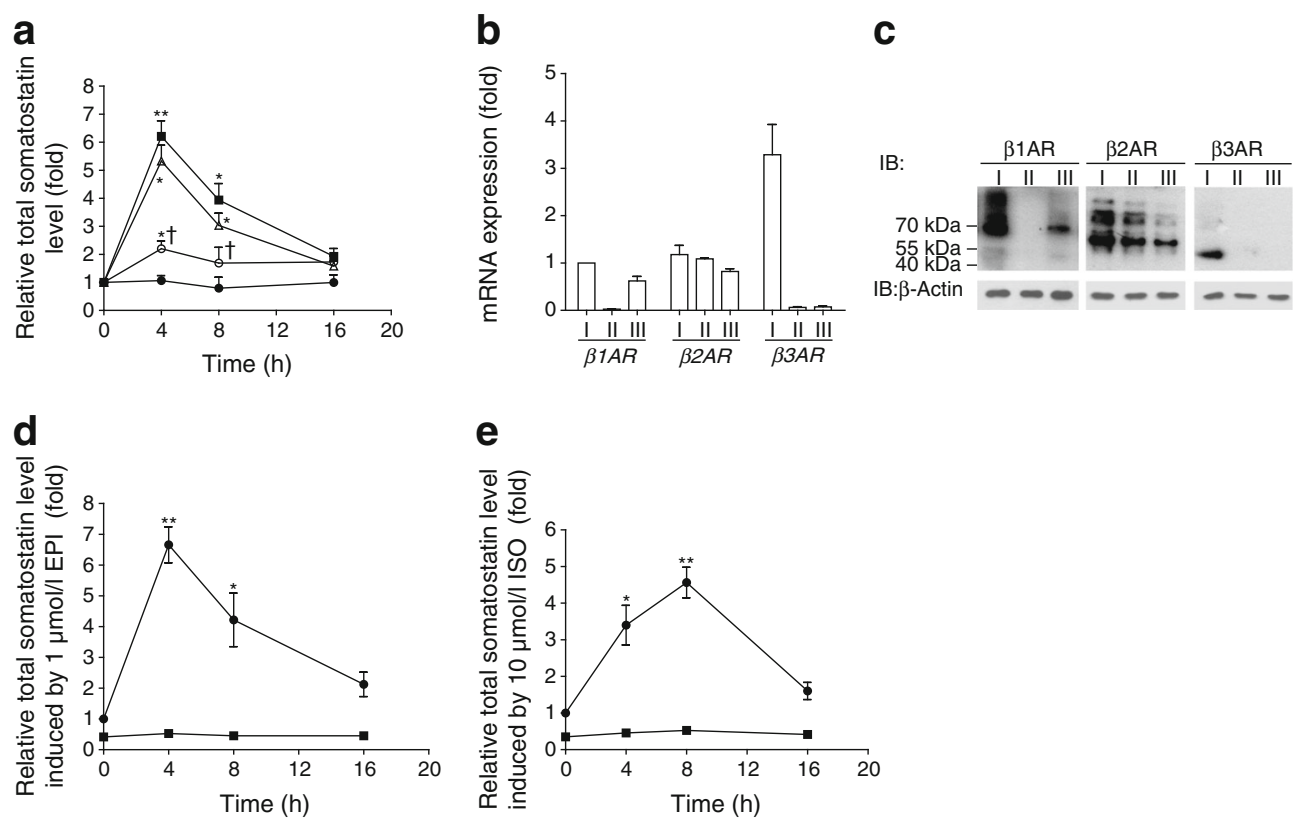

Fig. 1 Activation of the adrenergic system increased the somatostatin level through $\beta 1 \mathrm{ARs}$ and $\beta 2 \mathrm{ARs}$. (a) ELISA determination of the somatostatin level in islets (includes both islet somatostatin content and secreted fraction). Islets ( 80$)$ from C57BL/6 mice $(n=8)$ were stimulated with $1 \mu \mathrm{mol} / 1$ adrenaline, adrenaline $+10 \mu \mathrm{mol} / 1$ phentolamine or adrenaline $+10 \mu \mathrm{mol} / 1$ propranolol. Black circles, non-stimulated islets; squares, adrenaline; triangles, adrenaline+ phentolamine; white circles, adrenaline+propranolol. (b, c) The mRNA (b) and protein levels (c) of $\beta 1 \mathrm{AR}, \beta 2 \mathrm{AR}$ and $\beta 3 \mathrm{AR}$ in the mouse muscle tissue (I), the pancreatic

beta cell line MIN6 (II) or the pancreatic delta cell line TGP52 (III) were determined by quantitative real-time PCR or western blotting; IB, immunoblot. (d, e) Effects of adrenaline (EPI) (d) or isoprenaline (ISO) (e) on the somatostatin levels in the isolated islets (80) from $\beta 1 A R^{-1-} / \beta 2 A R^{-1-}$ mice $(n=6$ or 7$)$ or their wild-type littermates $(n=8)$. Circles, $\beta 1 A R^{+/+}$, $\beta 2 A R^{+/+}$mice; squares, $\beta 1 A R^{-/-} / \beta 2 A R^{-/-}$mice. (a, d, e) ${ }^{*} p<0.05$ and ${ }^{* *} p<0.01$; compared with non-stimulated islets; ${ }^{\dagger} p<0.05$; compared with adrenaline 
on somatostatin transcription. These identified signalling pathways may have broader implications in maintaining cell-type specificity and pancreatic delta cell function.

\section{Methods}

Animals and islet isolation All animal care and experiments were reviewed and approved by the Animal Use Committee of Shandong University School of Medicine. Arrb1 ${ }^{-/}, \mathrm{Arrb2}^{-/-}$ and $\beta 2 A R^{-1-}$ (Adrb2 knockout) mice were obtained from R. J. Lefkowitz (Duke University, Durham, NC, USA) and G. Pei (Tongji University, Shanghai, China); $\beta 1 A R^{-/-} / \beta 2 A R^{-/-}$mice were purchased from the Jackson Laboratory (Bar Harbor, ME, USA). $\beta 1 A R^{-/-}$or $\beta 2 A R^{-1-}$ mice with a congenic C57BL/6 background were obtained by crossing $\beta 1 A R^{-1-}$ / $\beta 2 A R^{-1-}$ mice with a $\mathrm{C} 57 \mathrm{BL} / 6$ background as described previously $[5,10]$. Islets were isolated from adult mice using collagenase $\mathrm{P}$ as described previously $[11,12]$. Detailed information on the animals and islet isolation are described in the electronic supplementary material (ESM) Methods.

Cell culture conditions and treatments TGP52 cells or isolated islets were exposed to the adrenergic agonists and/or antagonists for the entire time before they were harvested. See
ESM Methods for details regarding cell culture and chemical usage.

Somatostatin measurement Twenty/eighty islets were treated with adrenaline and/or other reagents, collected at the indicated time points and boiled at $100^{\circ} \mathrm{C}$ for $15 \mathrm{~min}$ to measure the cellular contents; the supernatant fraction was collected to measure the secreted fractions. See ESM Methods for additional details.

GloSensor cAMP assay See ESM Methods for details.

Quantitative real-time PCR, immunoprecipitation and western blotting Total RNA from TGP52 cells, MIN6 cells, mouse islets and muscle cells was extracted with TRIzol reagent (Invitrogen, Carlsbad, CA, USA). cDNA synthesis and PCR amplification were performed by quantitative realtime PCR using the Revertra Ace qPCR RT Kit (Toyobo FSQ101, Osaka, Japan), according to the manufacturer's protocols. Quantitative real-time PCR was conducted in the LightCycler qPCR apparatus (Bio-Rad, Hercules, CA, USA) using the FastStart Universal SYBR Green Master (Roche, Basel, Switzerland). Protein extracts or immune-precipitated samples were subjected to SDS-PAGE and western blotting. The lists of the primer sequences and the antibodies are
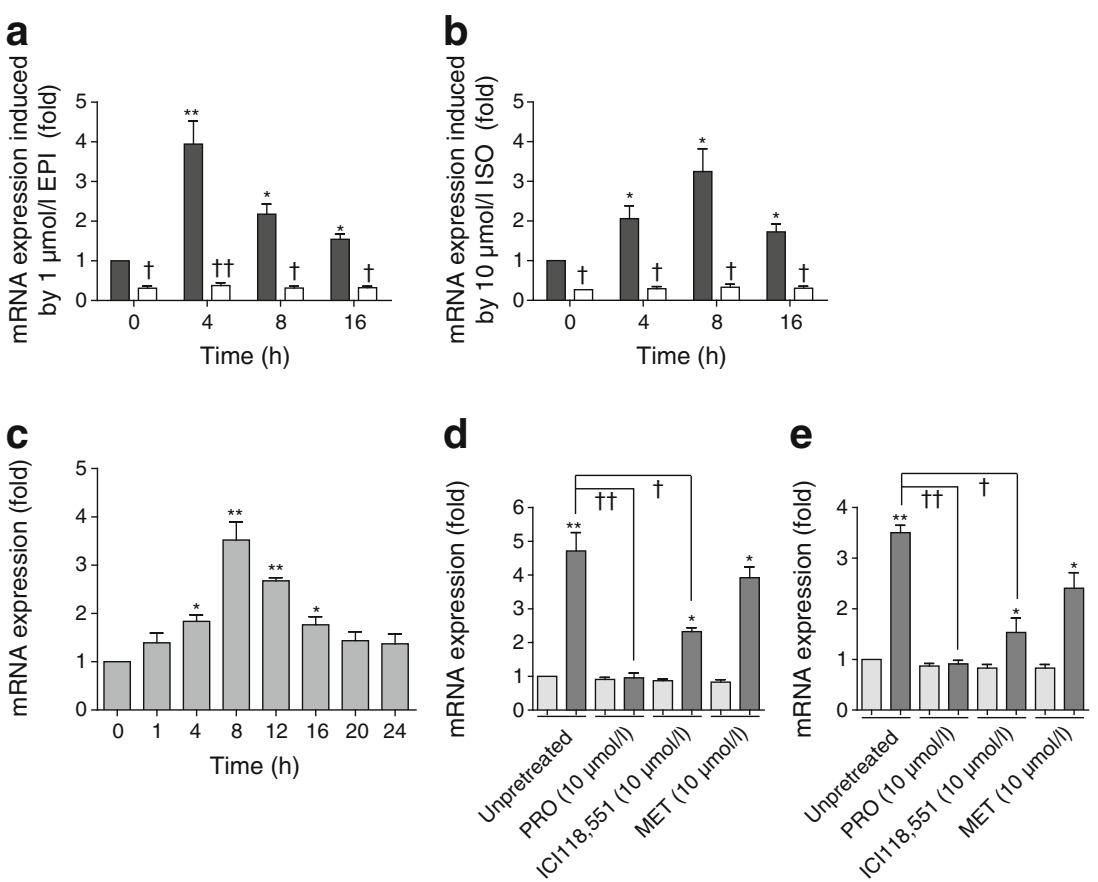

Fig. 2 Activation of the adrenergic system increased the somatostatin mRNA level in islets and TGP52 cells. (a, b) The mRNA levels of somatostatin were measured in the isolated islets by quantitative real-time PCR. Islets (80) isolated from $\beta 1 A R^{-/-} / \beta 2 A R^{-/-}$mice $(n=6)$ or their wildtype littermates $(n=6)$ were stimulated with adrenaline (EPI) (a) or isoprenaline (ISO) (b). Black bars, $\beta 1 A R^{+/+} / \beta 2 A R^{+/+}$mice; white bars, $\beta 1 A R^{-/-} / \beta 2 A R^{-/-}$mice. (c) Time course of $10 \mu \mathrm{mol} / 1$ isoprenaline-induced somatostatin mRNA increase in the TGP52 cells. (d, e) Effects of different $\beta$-adrenergic receptor blockers on the $1 \mu \mathrm{mol} / 1$ adrenaline/ $10 \mu \mathrm{mol} / \mathrm{l}$ isoprenaline-induced somatostatin mRNA increases in isolated islets (80) from wild-type mice (C57BL, $n=8)$. MET, metoprolol; PRO, propranolol. Light-grey bars, non-isoprenaline/adrenaline-stimulated cells; dark-grey bars, adrenaline (d) or isoprenaline (e). ${ }^{*} p<0.05$ and ${ }^{* *} p<0.01$ compared with the non-isprenaline/adrenaline-stimulated cells; ${ }^{\dagger} p<0.05$ and ${ }^{\dagger \dagger} p<0.01$ compared with the isoprenaline/adrenaline (only)stimulated cells 
a

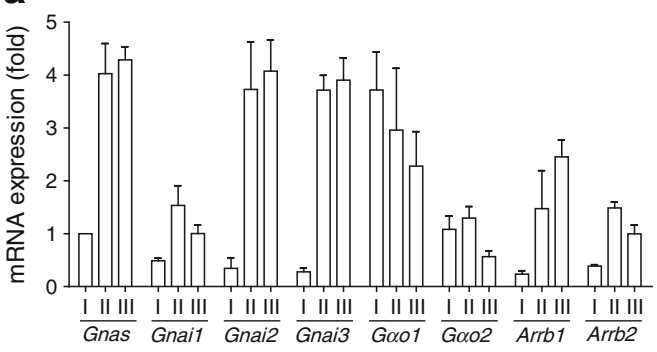

C

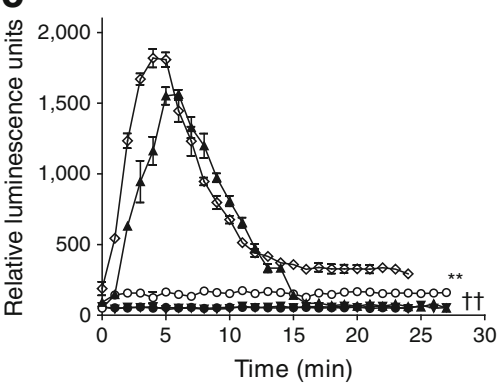

d
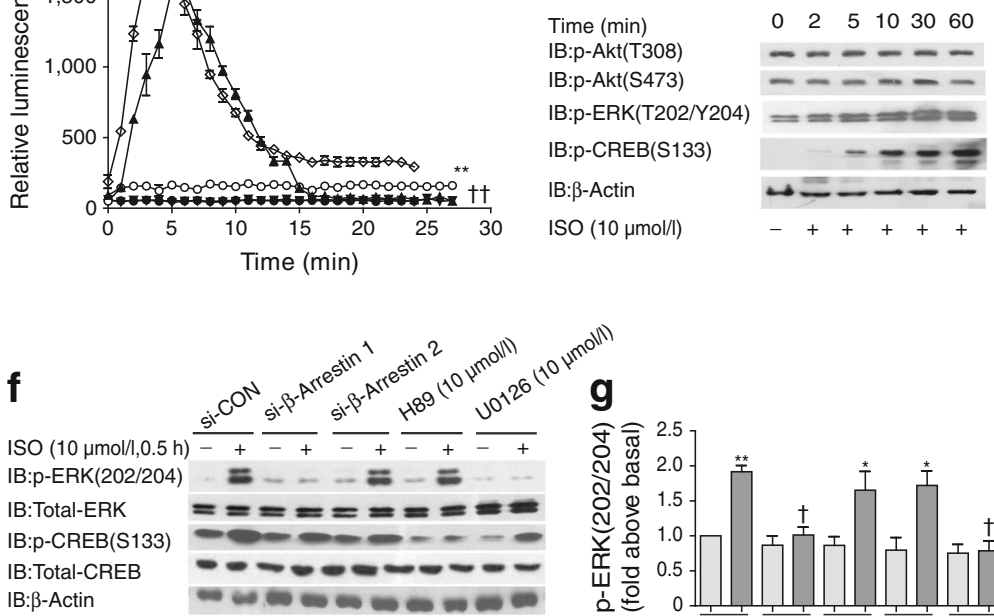

IB: $\beta$-Actin

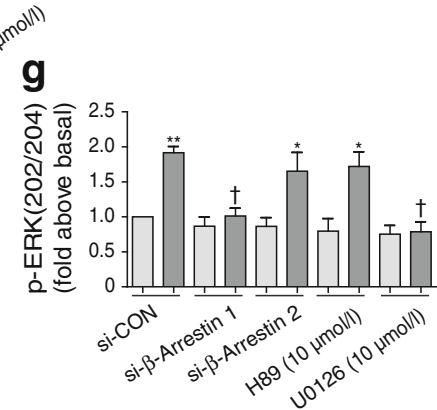

b

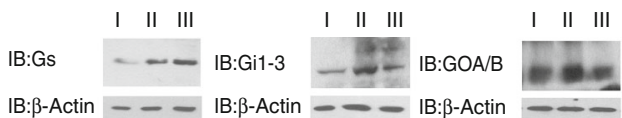

IB: $\beta$-Arrestin $1=-$

IB: $\beta$-Actin $\quad-\quad-$

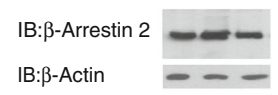

e

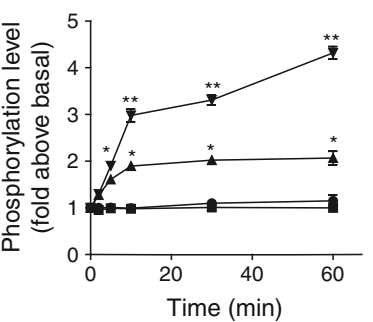

h

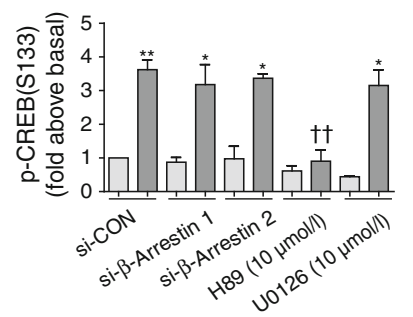

i

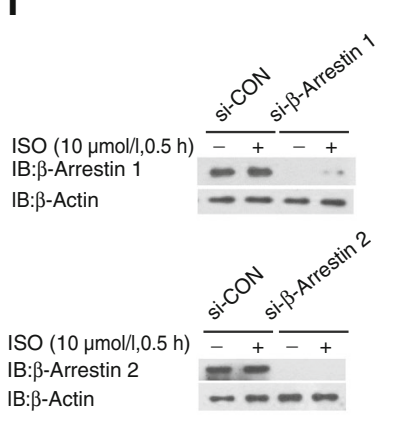

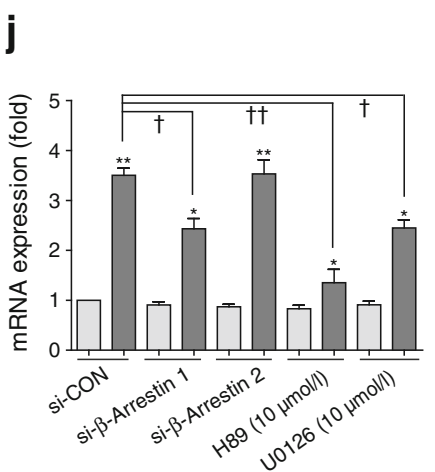

k

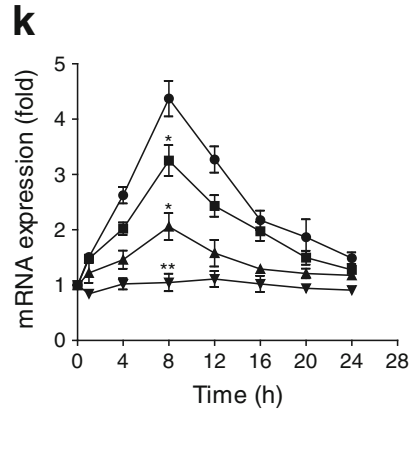

available in ESM Tables 1 and 2; see ESM Methods for additional details.

Constructs and luciferase assay See ESM Methods for details.

Data analysis All data are presented as the means $\pm \mathrm{SD}$ of at least three independent experiments. Statistical comparisons were carried out using ANOVA with GraphPad Prism5 software (www.graphpad.com/company/, USA). Differences were considered significant at ${ }^{*, \dagger} p<0.05$ and $* *, \dagger \dagger p<0.01$. The sequence alignments were performed using the T-coffee multiple sequence alignment program (www.expasy.org/, Switzerland).

\section{Results}

Activation of the adrenergic system increased the somatostatin level in the islets of Langerhans Incubating the islets with 
4 Fig. 3 Coordinated regulation of somatostatin transcription by the GsPKA-CREB and $\beta$-arrestin $1-$ ERK signalling pathways. $(\mathbf{a}, \mathbf{b})$ Expression of several important signalling components downstream of the $\beta$-ARs in mouse muscle tissue, MIN6 cells or TGP52 cells. mRNA levels were determined by quantitative real-time PCR (official gene symbols Gnas, Gnail, Gnai2, Gnai3, Gao1, Gao2) (a) and protein levels were determined by western blotting (b). (c) GloSensor assay was used to examine the dynamic effects of isoprenaline on the cAMP level in TGP52 cells with different $\beta$-adrenergic blockers. Black circles, control; white diamonds, $10 \mu \mathrm{mol} / 1$ isoprenaline; inverted black triangles, $10 \mu \mathrm{mol} / 1$ isoprenaline and $10 \mu \mathrm{mol} / 1$ propranolol; white circles, $10 \mu \mathrm{mol} / 1$ isoprenaline and $10 \mu \mathrm{mol} / 1 \mathrm{ICI} 118,551$; black triangles, $10 \mu \mathrm{mol} / 1$ isoprenaline and $10 \mu \mathrm{mol} / 1$ metoprolol. (d) Effects of isoprenaline (ISO) stimulation on the phosphorylation level of ERK $\left(\mathrm{pT}^{202} \mathrm{pY}^{204}\right)$, Akt $\left(\mathrm{pT}^{308}\right.$ and $\mathrm{pS}^{473}$ ) and CREB $\left(\mathrm{pS}^{133}\right)$. (e) Signals from (d) were quantified and expressed as a ratio relative to the phosphorylation level without stimulation. Black circles, $\mathrm{pT}^{308}$-Akt; black squares, $\mathrm{pS}^{473}$-Akt; inverted black triangles, $\mathrm{pS}^{133}$-CREB; black triangles, $\mathrm{pT}^{202} \mathrm{pY}^{204}$-ERK. (f-i) Effects of $\beta$-arrestin 1 knockdown, $\beta$ arrestin 2 knockdown, H89 or U0126 on isoprenaline-induced ERK and CREB phosphorylation in TGP52 cells. (f) The phosphorylation level of ERK-pT ${ }^{202} \mathrm{pY}^{204}$ or CREB-pS ${ }^{133}$. (g, h) Quantification of the phosphoERK levels or the phospho-CREB levels from (f). (i) Reduction of endogenous $\beta$-arrestin 1 or $\beta$-arrestin 2 protein levels by siRNA treatment. (j). Effects of $\beta$-arrestin 1 knockdown, $\beta$-arrestin 2 knockdown, H89 or U0126 on somatostatin mRNA levels in TGP52 cells measured by quantitative real-time PCR. (g, h, j) $* p<0.05$ and ${ }^{* *} p<0.01$ compared with non-isoprenaline-stimulated cells; ${ }^{\dagger} p<0.05$ and ${ }^{\dagger} p<0.01$ compared with isoprenaline (only)-stimulated controlsiRNA-treated cells. Light-grey bars, non-isoprenaline-stimulated cells; dark-grey bars, $10 \mu \mathrm{mol} / 1$ isoprenaline. (k) Effects of U0126, H89 or $\mathrm{U} 0126+\mathrm{H} 89$ on isoprenaline-induced somatostatin mRNA increase determined by quantitative real-time PCR. ${ }^{*} p<0.05$ and ${ }^{* *} p<0.01$ compared with the non-inhibitor-treated cells. Black circles, control; black squares, $10 \mu \mathrm{mol} / 1$ isoprenaline and $10 \mu \mathrm{mol} / 1 \mathrm{U} 0126$; black triangles, $10 \mu \mathrm{mol} / \mathrm{l}$ isoprenaline and $10 \mu \mathrm{mol} / 1 \mathrm{H} 89$; inverted black triangles, $10 \mu \mathrm{mol} / 1$ isoprenaline, $10 \mu \mathrm{mol} / 1 \mathrm{U} 0126$ and $10 \mu \mathrm{mol} / 1 \mathrm{H} 89$. IB, immunoblot; si-CON, control siRNA

adrenaline increased the somatostatin level between 4 and $8 \mathrm{~h}$ (Fig. 1a and ESM Fig. 1). Whereas the $\beta$-adrenergic blocker propranolol significantly decreased the effect of adrenaline, the $\alpha$-adrenergic blocker phentolamine produced no detectable change (Fig. 1a). Specific $\beta$-adrenergic agonism by isoprenaline stimulation also significantly elevated the somatostatin level in the islets but with a different peak time, which may be due to its greater effectiveness in the stabilisation of the receptor-effector complex when compared with adrenaline (Fig. 1e and ESM Fig. 2) [13].

There are three $\beta$-adrenergic receptors in humans that respond to isoprenaline stimulation. The mRNA and protein levels of both the $\beta 1$ - and $\beta 2$-adrenergic receptor ( $\beta 1 \mathrm{AR}$ and $\beta 2 \mathrm{AR}$ ) were lower, but detectable, in the pancreatic somatostatin-containing cell line (TGP52) compared with the muscle cells; however, the expression of $\beta 3$-adrenergic receptor ( $\beta 3 \mathrm{AR}$ ) was significantly lower (Fig. 1b, c and ESM Fig. 3). The isolated islets from the $\beta 1 A R^{-/-} / \beta 2 A R^{-/-}$mice or the $\beta 2 A R^{-/-}$mice consistently showed a much lower response to adrenaline or isoproterenol treatment compared with the islets from control mice (Fig. 1d, e and ESM Fig. 2). The $\beta 1 A R^{-1-}$ mice had a decreased response to adrenaline/ isoprenaline but this effect was much lower compared with that of $\beta 2$ AR deficiency (ESM Fig. 1). Moreover, the somatostatin level in the $\beta 1 A R^{-/-} / \beta 2 A R^{-/-}$mice or the $\beta 2 A R^{-/-}$mice was at least $50 \%$ lower compared with the level in the $\beta 1 A R^{+/ 4} / \beta 2 A R^{+/+}$or the wild-type mice in the unstimulated state, suggesting an essential role for $\beta$-agonism in maintaining normal somatostatin levels in vivo (Fig. 1d, e and ESM Fig. 1). Taken together, these data indicate that the adrenergic system is important for the maintenance and regulation of somatostatin level in delta cells, mainly through the activation of $\beta 1$ - and $\beta 2$ ARs.

Activation of the adrenergic system increases somatostatin $m R N A$ level We next determined whether the transcription of somatostatin was upregulated by adrenaline and isoprenaline. The application of either adrenaline or isoprenaline significantly increased the somatostatin mRNA level (Fig. 2a-c and ESM Fig. 4). The increased somatostatin mRNA level was predominantly due to the activation of somatostatin transcription, as the application of actinomycin-D abolished the effects of adrenaline/isoprenaline on the somatostatin mRNA level (ESM Fig. 5). Furthermore, $\beta 1 \mathrm{AR}$ and $\beta 2 \mathrm{AR}$ deficiency in the $\beta 1 A R^{--} / \beta 2 A R^{-1-}$ mice abolished the effects of both adrenaline and isoprenaline on somatostatin mRNA level (Fig. 2a, b). We next used specific $\beta$-adrenergic receptor antagonists to dissect the contribution of each receptor to somatostatin transcriptional activation. The application of either the $\beta 2 A R$ antagonist ICI118,551 or the $\beta 1$ AR antagonist metoprolol significantly reduced, but did not abolish, the isoprenaline/adrenaline-induced increase in somatostatin mRNA (Fig. 2d, e). Blockade of both $\beta 1$ - and $\beta 2$ ARs by the non-selective $\beta$-blocker propranolol eliminated the isoprenaline-induced effects (Fig. 2e). Therefore, the combined activation of both $\beta 1$ - and $\beta 2$ ARs mediates the adrenergic effects on the somatostatin mRNA increase, predominantly through transcription.

Synergic regulation of somatostatin transcription by the $G s$-protein kinase-CREB and $\beta$-arrestin 1-extracellular signal-related kinase signalling pathways In general, activated $\beta 1$ - and $\beta 2$ ARs primarily couple to Gs, initiating the adenylate cyclase (AC)-cAMP-protein kinase A (PKA) signalling pathway, which results in the 'first wave' of cellular effects [14-16]. In addition, $\beta 2$ ARs can also activate Gi signalling or form receptor-arrestin complexes to initiate the 'second wave' of signalling [16, 17].

We investigated the expression of key effectors downstream of the $\beta$-adrenergic receptors. Compared with the pancreatic beta cell line MIN6, the pancreatic delta cell line TGP52 had similar expression levels of Gs/Gnas, Gi2/Gnai2, Gi3/Gnai3 and $\beta$-arrestin 2, lower levels of Gi1/Gnail, GOA/ Gaol and GOB/Gao2 and higher levels of $\beta$-arrestin 1 
(Fig. 3a, b and ESM Fig. 6). We then monitored the kinetics of the isoprenaline-induced intracellular cAMP changes. Application of isoprenaline significantly increased cellular cAMP levels in pancreatic delta cells (Fig. 3c). Propranolol or ICI118,551 treatment significantly decreased the isoprenaline-induced cAMP increase, whereas application of metoprolol alone reduced the effect of isoprenaline on cAMP levels at early time points. The phosphorylation of CREB at S133 was significantly increased, consistently, downstream of the cAMP-PKA pathway (Fig. 3d). In addition to inducing CREB phosphorylation, $\beta$-adrenergic agonism also activates
Akt and extracellular signal-related kinase (ERK) [5, 17, 18]. In contrast to the two phases of ERK activation by glucagonlike peptide 1 in the pancreatic beta cells, ERK activation induced by isoprenaline treatment in TGP52 cells is monophasic [19]. Akt phosphorylation in our study, however, showed no significant change (Fig. 3d, e). Further, application of the PKA inhibitor H89 selectively blocked isoprenalineinduced CREB phosphorylation, and the knockdown of endogenous $\beta$-arrestin 1 levels, but not $\beta$-arrestin 2 levels or the inhibition of PKA activity, selectively inhibited ERK phosphorylation (Fig. 3f-i). Therefore, Gs-cAMP-PKA-CREB a

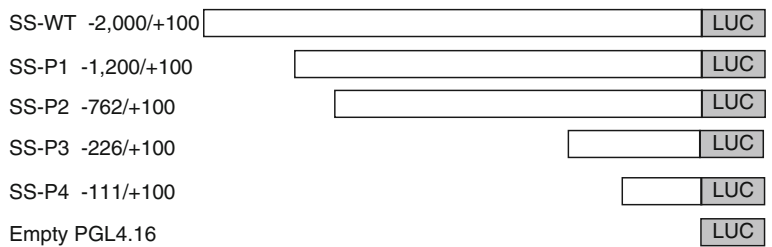

\section{C}

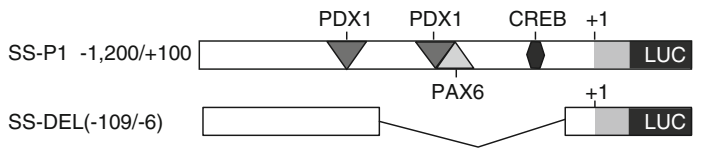

d

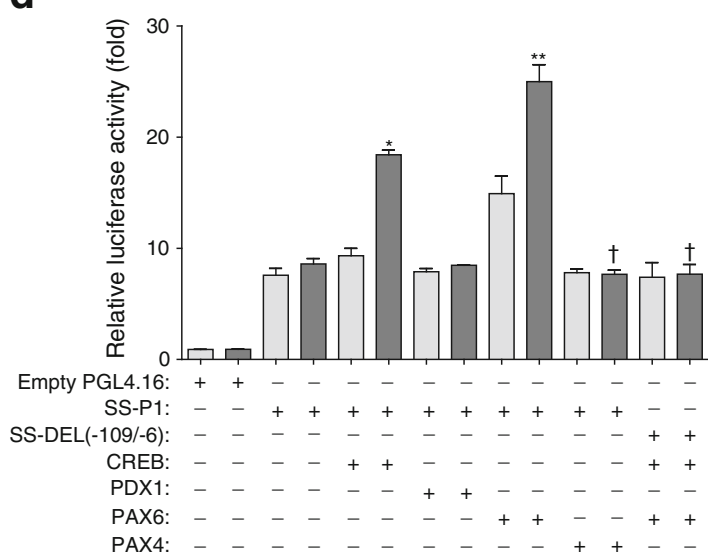

b

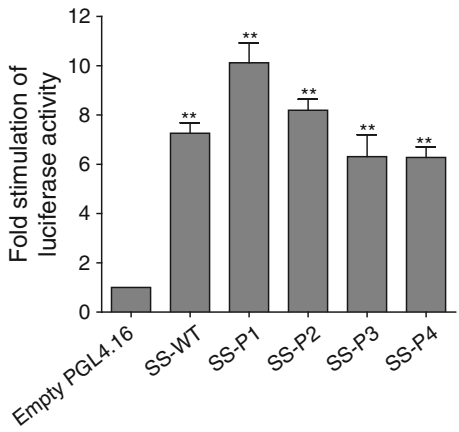

e

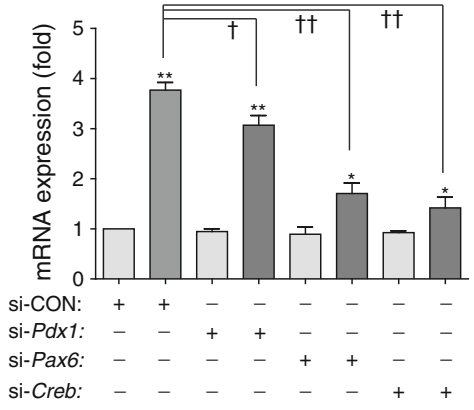

f

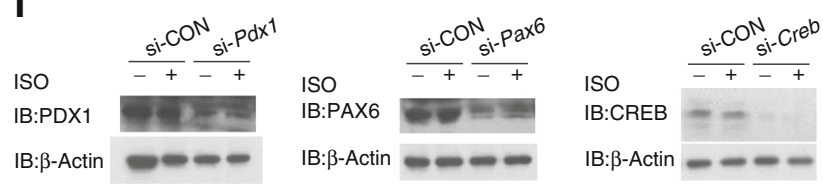

Fig. 4 Transcription factors PAX6 and CREB mediated the isoprenalineinduced somatostatin mRNA increase. (a) Schematic representation of the mouse somatostatin promoter truncations used in the luciferase assays. (b) Luciferase activity of the different somatostatin promoter truncations with $10 \mu \mathrm{mol} / 1$ isoprenaline stimulation. Luciferase activity was normalised to that of Renilla luciferase, ${ }^{* *} p<0.01$ compared with the empty PGL4.16. (c) Putative schematic depiction of the CREB, PDX1 and PAX6 binding positions in the somatostatin upstream enhancer (SSUE) in mouse somatostatin. (d) Effects of overexpression of different transcription factors (PDX1, PAX6, PAX4 or CREB) on the isoprenalineinduced luciferase activity. (e) Effects of siRNA knockdown of PDX1, PAX6 and CREB on the somatostatin mRNA levels with $10 \mu \mathrm{mol} / 1$ isoprenaline stimulation. (d, e) $* p<0.05$ and $* * p<0.01$ compared with the non-isoprenaline-stimulated cells; ${ }^{\dagger} p<0.05$ and ${ }^{\dagger \dagger} p<0.01$ compared with the control siRNA-treated cells. Light-grey bars, non-isoprenalinestimulated cells; dark-grey bars, isoprenaline. (f) Reduction of endogenous PDX1, PAX6 or CREB protein levels by siRNA treatment. IB, immunoblot; si-CON, control siRNA 
and $\beta$-arrestin 1-ERK are two parallel signalling pathways downstream of $\beta$-agonism in TGP52 cells. Moreover, the knockdown of $\beta$-arrestin 1 or the application of the PKA inhibitor H89 or the ERK pathway inhibitor U0126 significantly reduced the isoprenaline-induced somatostatin mRNA increase (Fig. 3j, k and ESM Fig. 7). The combination of U0126 and H89 eliminated the effects of isoprenaline (Fig. 3k). Taken together, these data indicate that two signalling pathways, Gs-cAMP-PKA-CREB and $\beta$-arrestin 1 -ERK, cooperatively mediate the effects of $\beta$-agonism on somatostatin transcription.

PAX6 and CREB mediate isoprenaline-induced somatostatin transcription To define the minimal promoter region of somatostatin needed for the response to isoprenaline in pancreatic delta cells, we generated a series of 5 '-deletion constructs and fused them to firefly luciferase to evaluate their activity in TGP52 cells (Fig. 4a, b). Deletion of $-2,000$ to $-1,200$ increased the isoprenalineinduced somatostatin luciferase activity, suggesting a negative control element in this upper promoter region. Deletion between $-1,200$ and -226 reduced promoter activity by $30 \%$ and deletion between -109 and -8 abolished somatostatin promoter activity (Fig. 4a-c). Therefore, the essential positive control elements for isoprenaline-induced somatostatin transcription are primarily localised between -109 and -6 , and additional positive control elements reside between -226 and $-2,000$.

The somatostatin promoter region between -109 and -6 encompasses the cAMP response element (CRE) enhancer and domains $\mathrm{B} / \mathrm{C}$ of the SMS-UE enhancer [20]. Three transcriptional factors, CREB, pancreatic and duodenal homeobox 1 (PDX1) and PAX6, have been identified as binding to the somatostatin promoter region between -109 and 100 [20-22] (Fig. 4c). We then transfected the SS-P1 luciferase construct, which confers the maximal isoprenaline-induced transcriptional activity, together with CREB, PDX1, or PAX6 in TGP52 cells. Isoprenaline-promoted SS-P1 transcriptional luciferase activity significantly increased upon co-transfection with CREB or PAX6, but not with PDX1 or PDX4 (Fig. 4d and ESM Fig. 8). Deletion of the -109 to -6 region abolished the effects of CREB and PAX6 (Fig. 4c, d). Moreover, whereas the knockdown of PDX1 had little effect on the isoprenaline-induced somatostatin mRNA increase, the knockdown of PAX6 or CREB levels significantly decreased the effects of isoprenaline (Fig. 4e, f). Therefore, PAX6 and CREB are required for $\beta$-agonism-promoted somatostatin transcription by interacting with the -109 to +100 region of the somatostatin promoter.

Regulation of somatostatin promoter activity by the isoprenaline-PKA-CREB signalling pathway CREB is a well-
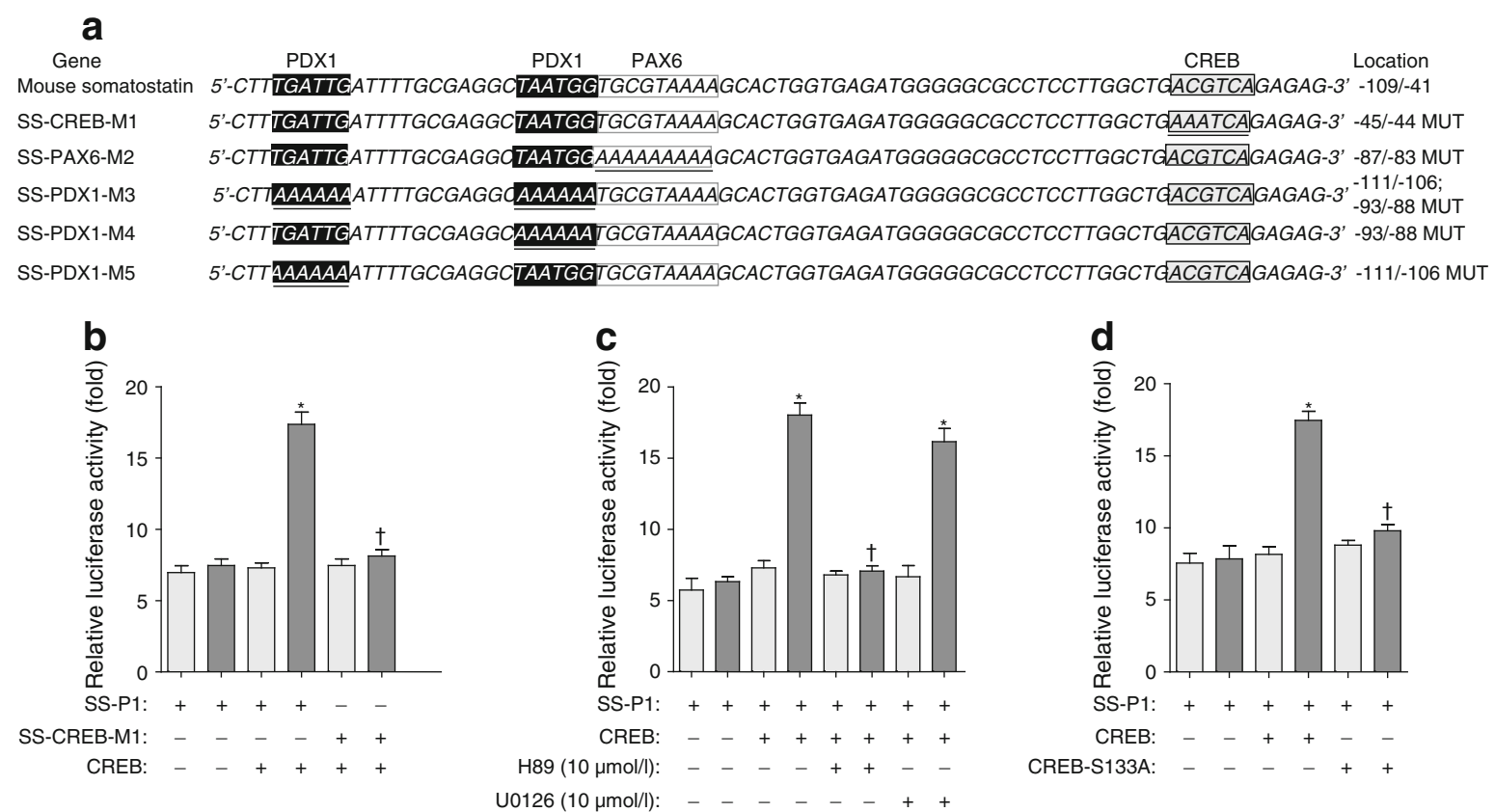

Fig. 5 Phosphorylation of CREB at S133 contributed to isoprenalineinduced somatostatin transcription. (a) Putative sequence representation of the mouse SS-UE somatostatin promoter from -109 to -41 . Lines indicate the SMS-UE sites for PDX1, PAX6 and CREB binding. (b) Isoprenaline-induced luciferase activity of the somatostatin promoter SSP1 and SS-CREB-M1 in the context of CREB overexpression. ${ }^{*} p<0.05$ compared with non-stimulated cells. ${ }^{\dagger} p<0.05$ compared with SS-P1. (c) Effects of U0126 or H89 on the CREB-mediated SS-P1 luciferase activity. ${ }^{*} p<0.05$ compared with non-stimulated cells. ${ }^{\dagger} p<0.05$ compared with non-inhibitor-treated cells. (d) Effects of CREB-S133A mutation on the isoprenaline-induced luciferase activity of the somatostatin promoter. ${ }^{*} p<0.05$ compared with non-stimulated cells; ${ }^{\dagger} p<0.05$, CREB-S133A mutant-transfected cells compared with CREB WTtransfected cells. (b-d) Light-grey bars, non-isoprenaline-stimulated cells; dark-grey bars, $10 \mu \mathrm{mol} / \mathrm{l}$ isoprenaline 
a

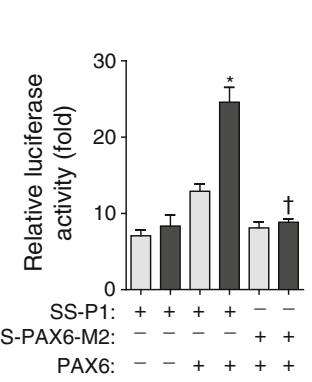

b

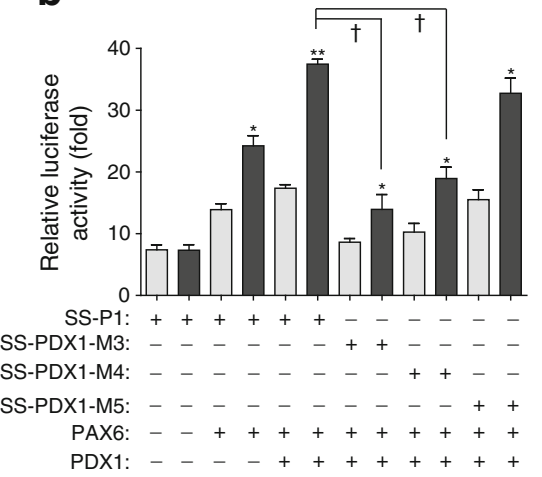

C

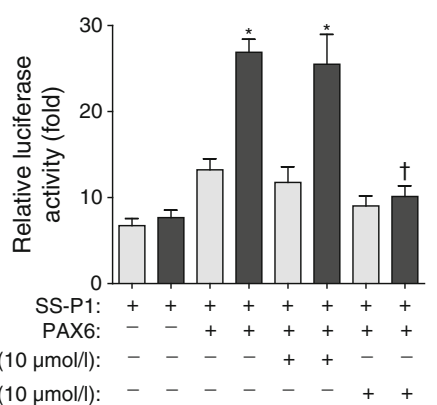

d

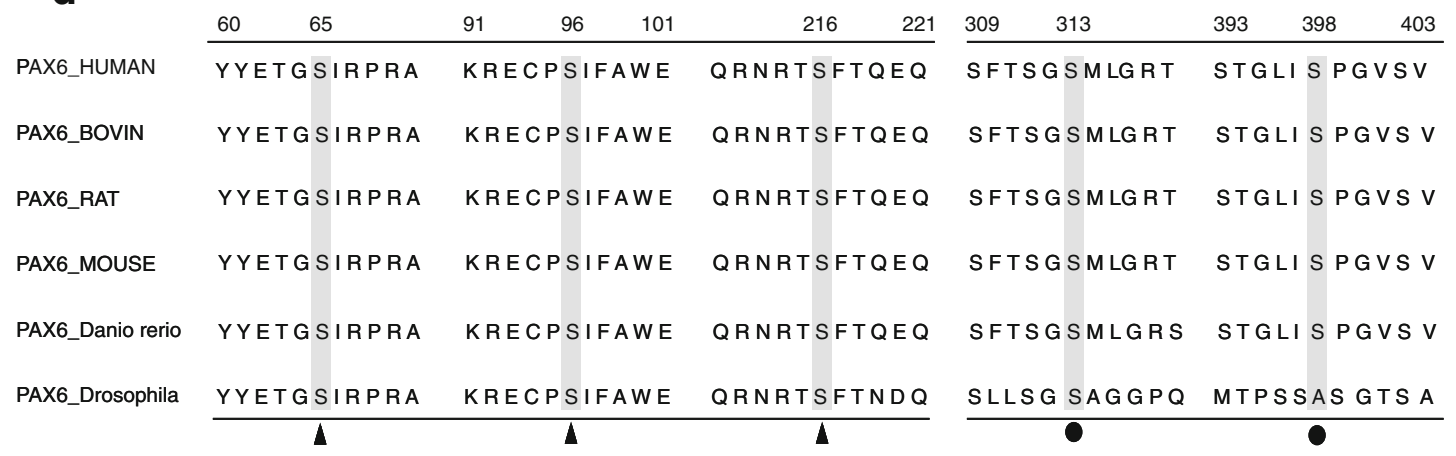

e

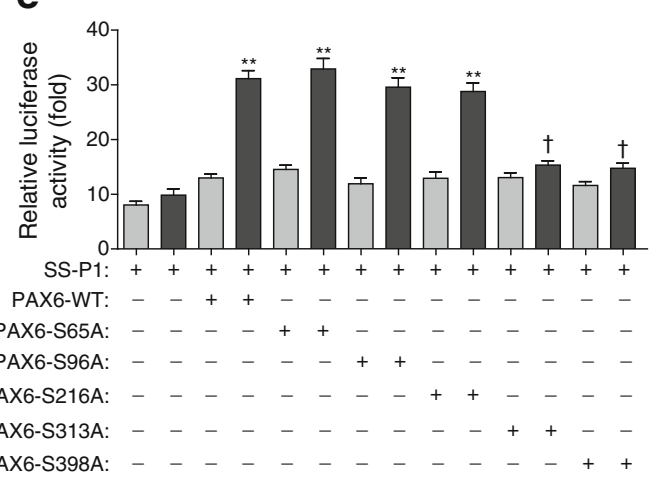

f

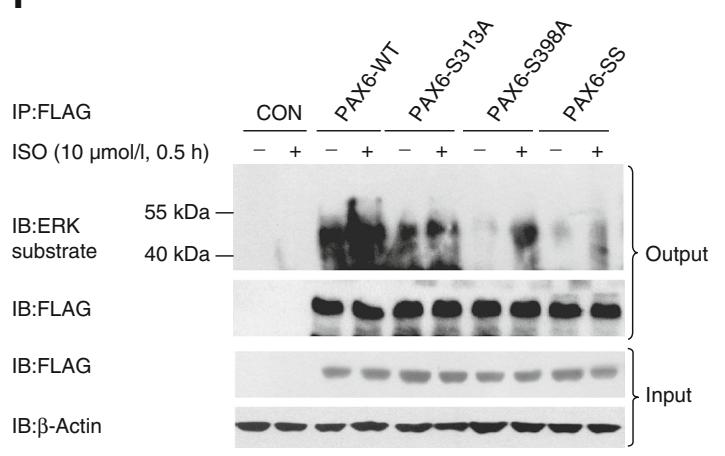

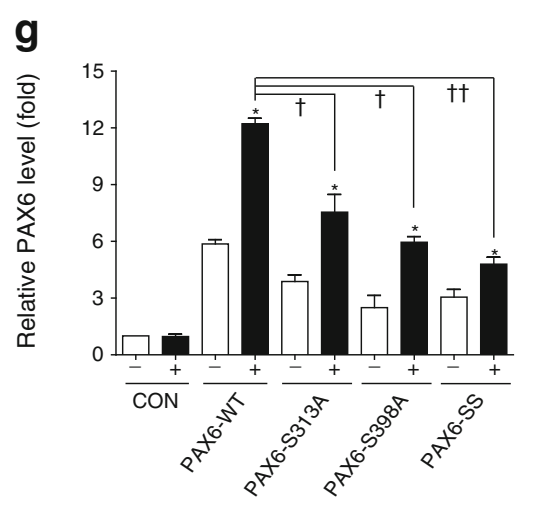

h

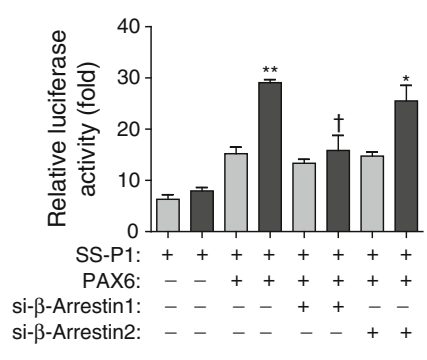

known regulator of somatostatin transcription [21, 23]. The consensus CRE ACGTCA between -51 and -45 of the somatostatin promoter is the CREB binding site (Fig. 5a). Accordingly, mutation of the CRE abolished
CREB-mediated SS-P1 luciferase activity (Fig. 5b and ESM Fig. 9a).

Phosphorylation of CREB at position 133 by PKA has been established as a critical step for the activation of 
Fig. 6 Regulation of isoprenaline-stimulated somatostatin transcription by the $\beta$-arrestin 1-ERK-PAX6 pathway. (a) Isoprenaline-induced luciferase activity of SS-P1 and SS-PAX6-M2 in the context of PAX6 overexpression. (b) Isoprenaline-induced luciferase activity of SS-P1, SS-PDX1-M3, SS-PDX1-M4 and SS-PDX1-M5 in the context of PAX6 or PDX1 co-transfection. (a, b) $* p<0.05$ and $* * p<0.01$ compared with non-stimulated cells; ${ }^{\dagger} p<0.05$ compared with SS-P1. (c) Effects of U0126 or H89 on PAX6-mediated SS-P1 luciferase activity. ${ }^{*} p<0.05$ compared with non-stimulated cells; ${ }^{\dagger} p<0.05$ compared with non-inhibitor-treated cells. (d) Sequence alignment of the potential ERK phosphorylation sites in PAX6 between different species. (e) Effects of different PAX6 mutations on the isoprenaline-induced luciferase activity of the somatostatin promoter. ${ }^{*} p<0.05$ compared with non-stimulated cells; ${ }^{\dagger} p<0.05$, PAX6-mutant-transfected cells compared with PAX6WT-transfected cells. (a-c, e) Light-grey bars, control; dark-grey bars, $10 \mu \mathrm{mol} / 1$ isoprenaline. (f) PAX6 phosphorylation by isoprenaline induced ERK activation. Flag-tagged PAX6-WT and different mutants were immune-precipitated by Flag antibody and detected by anti-phospho MAPK/CDK substrate antibody; IB, immunoblot; IP, immunoprecipitate. (g) Quantification of (f). ${ }^{*} p<0.05$ compared with the non-isoprenalinestimulated cells; ${ }^{\dagger} p<0.05$ and ${ }^{\dagger \dagger} p<0.05$ compared with PAX6-WT. White bars, control; black bars, $10 \mu \mathrm{mol} / 1$ isoprenaline. (h) Effects of $\beta$-arrestin 1 or $\beta$-arrestin 2 knockdown on the PAX6-mediated somatostatin promoter activity. ${ }^{*} p<0.05$ and $* * p<0.01$ compared with nonstimulated cells; ${ }^{\dagger} p<0.05, \beta$-arrestin siRNA-treated cells compared with control-siRNA-treated cells. Light-grey bars, control; dark-grey bars, $10 \mu \mathrm{mol} / \mathrm{l}$ isoprenaline somatostatin transcription by recruiting CREB to the transcriptional complex [21]. The CREB-mediated SS-P1 luciferase activity was specifically blocked by either H89 or cotransfection with the CREB-S133A mutant, but not the U0126 (Fig. 5c, d and ESM Fig. 9 b, c). Therefore, the PKA-CREB-pS ${ }^{133}$ signalling pathway underlies the isoprenaline-promoted somatostatin transcriptional activation.

$\beta$-Arrestin1/ERK-dependent PAX6 phosphorylation of $p S^{133}$ and $p S^{398}$ underlies isoprenaline-induced somatostatin promoter activity PAX6 and PDX1 have been reported to form a complex to regulate somatostatin promoter activity [22]. Mutation of the PAX6 binding site in the SMS-UE abolished the PAX6-mediated SS-P1 luciferase activity after isoprenaline stimulation (Fig. 6a and ESM Fig. 10a). Co-transfection with PAX6 and PDX1 further increased the isoprenaline-stimulated SS-P1 luciferase activity (Fig. 6b and ESM Fig 10b). Additionally, mutation in the PAX6 binding site or the neighbouring PDX1 binding site in SMS-UE, but not the remote $\mathrm{PDX} 1$ binding site, reduced the PAX6 activity (Fig. 6b). Therefore, the PAX6-PDX1-SMS-UE ternary
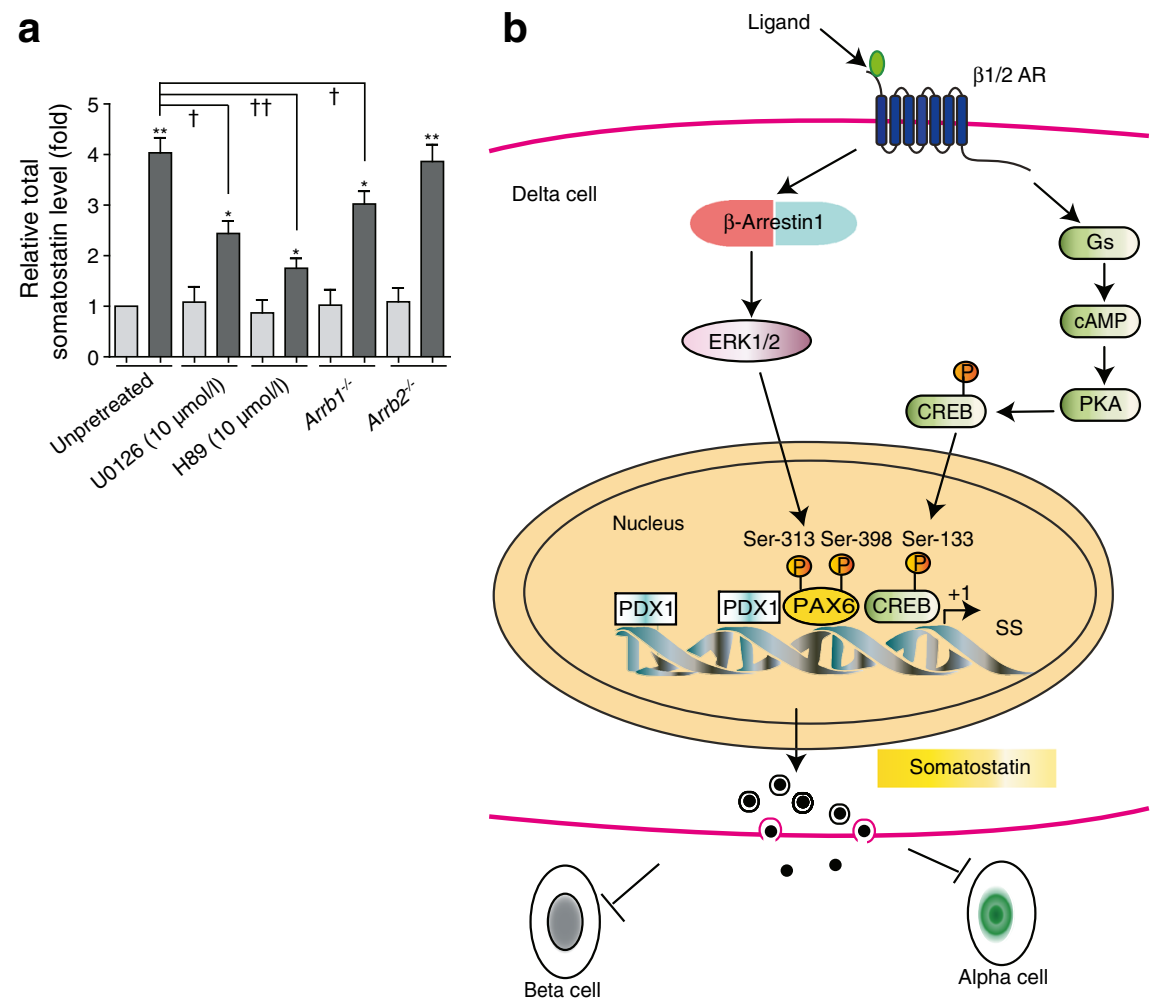

Fig. 7 Functional importance of PKA activity, ERK activity and $\beta$-arrestin 1 in isoprenaline-induced somatostatin increase. (a) ELISA determination of the $10 \mu \mathrm{mol} / 1$ isoprenaline-stimulated somatostatin increase in islets from wild-type mice (C57BL/ $6, n=8)$, islets pre-incubated with $\mathrm{U} 0126$ or $\mathrm{H} 89$ or islets from $\operatorname{Arrb1}^{-1-}$ mice or $\operatorname{Arrb2}^{--}$mice $(n=6)$. Batches of 20 islets each were stimulated with or without isoprenaline. Data represent at least three independent experiments and are presented as a ratio of the basal levels. ${ }^{*} p<0.05$ and ${ }^{* *} p<0.01$ compared with the non- isoprenaline-stimulated islets; ${ }^{\dagger} p<0.05$ and ${ }^{\dagger \dagger} p<0.01$, inhibitor or knockout mice compared with control mice. Light-grey bars, non-isoprenalinestimulated cells; dark-grey bars, isoprenaline. (b) Model of the adrenergic system activation in the regulation of the somatostatin level. The stress hormone adrenaline or the $\beta$-agonist isoprenaline binds and activates $\beta 1$ and $\beta 2$ ARs, which then activate two signalling pathways: the Gs-ACcAMP-PKA-CREB pathway and the $\beta$-arrestin 1 -ERK-PAX6 pathway 
complex mediated somatostatin transcription following stimulation with isoprenaline.

Within different inhibitor applications, H89 produced no significant difference in the PAX6-mediated SS-P1 luciferase activity; however, the specific ERK pathway inhibitor U0126 eliminated the PAX6-mediated response after the isoprenaline induction (Fig. 6c and ESM Fig. 10c). We then generated a series of PAX6 mutations at potential ERK phosphorylation sites and examined their effects (Fig. 6e and ESM Fig. 10d). Mutations in the N-terminal paired domain or paired-type homeodomain at S65, S96 or S216 had no effect on isoprenaline-induced PAX6 activity; however, mutations in the transactivation domain at either S313 or S398 abolished the PAX6 responses (Fig. 6e). Moreover, the isoprenalineinduced PAX6 phosphorylation by ERK was reduced in PAX6-S313A, PAX6-S398A and PAX6-S313A/S398A mutants (Fig. 6f, g). These data suggest that ERK phosphorylation of PAX6 at $\mathrm{pS}^{313}$ and $\mathrm{pS}^{398}$ regulates PAX6 activity in response to isoprenaline stimulation. Consistent with the important role of $\beta$-arrestin 1 in ERK activation after isoprenaline stimulation, reducing endogenous $\beta$-arrestin 1 levels impaired isoprenaline-induced PAX6 activity, whereas reducing endogenous $\beta$-arrestin 2 levels had little effect (Fig. $6 \mathrm{~h}$ and ESM Fig. 10e). Taken together, the $\beta$-arrestin 1-ERK signalling pathway phosphorylates PAX6 at S313 and S398, which underlies the PAX6-mediated transcription of somatostatin after isoprenaline stimulation.

Somatostatin increase induced by $\beta$-agonism is mediated by the PKA-CREB and $\beta$-arrestin 1-ERK pathways Finally, to understand the functional relevance of the PKA-CREB and the $\beta$-arrestin 1-ERK-PAX6 pathways in the increase in somatostatin content induced by $\beta$-agonism, we monitored the effects of isoprenaline on wild-type islets, islets pre-treated with $\mathrm{H} 89$ or U0126, or islets from $A r r b 1^{-/}$or $A r r b 2^{-1-}$ mice (Fig. 7b). Whereas there was no significant change in the Arrb2 $2^{-1}$ mice compared with the control C57BL mice, the application of either H89 or U0126 significantly reduced the isoprenaline-promoted somatostatin increase, and the $\mathrm{Arrb}^{-/-}$mice displayed a reduced somatostatin increase similar to the effects observed with application of U0126 (Fig. 7a). Taken together, these data indicate that both the PKA-CREB and the $\beta$-arrestin 1-ERK signalling pathways are required for the increase in somatostatin induced by $\beta$-agonism (Fig. 7b).

\section{Discussion}

The somatostatin level in pancreatic delta cells must be precisely regulated to fulfil the secretion demand. An imbalance between hormone release and synthesis can stress the secreting cells and impair their function. For example, longterm exposure of the beta cells to fatty acid-promoted insulin secretion in the presence of pre-insulin synthesis inhibition has been implicated in the development of diabetes [24]. Previous work has demonstrated that the acute presentation of the stress hormone adrenaline potently stimulates somatostatin release from pancreatic delta cells; this process forms part of the finely tuned signalling network that regulates the function of the islets of Langerhans $[6,7,9]$. However, it was not known whether adrenaline also increases somatostatin levels to fulfil the demand for somatostatin secretion. Here, we demonstrated that activation of the adrenergic system significantly increases the somatostatin level in pancreatic delta cells, mainly through the activation of $\beta 1$ - and $\beta 2 A R s$ (Figs 1 and 2). These results elucidate the fine-tuning mechanism for stress regulation of somatostatin content and transcription, in addition to its known role in somatostatin release. Moreover, we found that $\beta 1 A R^{-/-} / \beta 2 A R^{-/-}$mice had much lower somatostatin levels in islets when compared with their wild-type littermates. Therefore, $\beta$-adrenergic agonism is required for maintaining the normal somatostatin level in vivo, and a dysfunction in $\beta$-adrenergic agonism may impair the synchronised signalling network for the islets of Langerhans.

Downstream of $\beta 1 \mathrm{AR}$ and $\beta 2 \mathrm{AR}$ activation in a pancreatic delta cell line, we have identified two major signalling pathways that regulate somatostatin transcription. One is the GsPKA-CREB-pS ${ }^{133}$ pathway, and the other is the $\beta$-arrestin 1ERK-PAX6-pS ${ }^{313} \mathrm{pS}^{398}$ pathway (Fig. 7). The stronger effect of the rapid response of the Gs-PKA-CREB pathway, compared with the slower $\beta$-arrestin 1-ERK-PAX6-pS ${ }^{313} \mathrm{pS}^{398}$ pathway, may indicate an acute demand for an increased somatostatin level in the pancreatic delta cells in response to $\beta$-agonism (Fig. 7a). Moreover, the G-protein-coupled receptor (GPCR)-regulated PAX6 activity in somatostatin transcription has not been characterised [23, 25, 26]. Knockdown of PAX6 significantly reduced isoprenaline-induced somatostatin transcription, suggesting an essential role for PAX6 in the stress response, in agreement with its functional importance in maintaining pancreatic cell-type specificity and pancreatic development [27-30]. Using a series of mutations, previous studies have suggested that the $\mathrm{pT}^{322} \mathrm{pT}^{323}, \mathrm{pT}^{375} \mathrm{pS}^{376}$ and $\mathrm{pS}^{413}$ sites in zebra fish (corresponding to $\mathrm{pT}^{303} \mathrm{pT}^{304}$, $\mathrm{pT}^{360} \mathrm{pS}^{361}$ and $\mathrm{pS}^{398}$ in humans, respectively) are potential phosphorylation sites downstream of ERK [31]. However, only the phosphorylation of the S413 site shows functional relevance in the regulation of PAX6 transcriptional activity [31]. In addition to the functionally relevant S398 site, we demonstrated that phosphorylation of PAX6 on S313 is also required for PAX6-mediated somatostatin transcription (Fig. 5e). Future biochemical studies to characterise the functional importance of $\mathrm{pS}^{313}$ on PAX6 may provide further insights into the details of PAX6 regulation and somatostatin transcription. 
In addition to canonical G-protein signalling, the importance of $\beta$-arrestin-mediated (GPCR) signalling has recently been recognised [32-34]. New studies have revealed that $\beta$-arrestin 1 is a major downstream mediator of GPCRs, such as $\beta 2 A R$, GLP-1R, M3R and A1TaR, and is involved in genome stability, pancreatic beta cell function, podocyte activation and renal injury $[5,19,35,36]$. However, the functional importance of $\beta$-arrestin 1 in pancreatic delta cells had not been investigated. Here, we have demonstrated that $\beta$-arrestin 1/ERK signalling is one of the major players in the regulation of somatostatin transcription induced by $\beta$-agonism. Compared with $\mathrm{Arrbl}^{+/+}$mice, the $A r r b 1^{-/-}$mice showed a lesser response to the effects of isoprenaline on somatostatin increase (Fig. 7a). The $\beta$-arrestins are important regulators for GPCRs, which are activated by numerous physiological or pathological stimuli. Thus, $\beta$-arrestin-mediated somatostatin transcription may be a general mechanism downstream of many GPCRs in the regulation of pancreatic delta cell function.

Acknowledgements We thank R. J. Lefkowitz at Duke University, Durham, NC, USA and G. Pei at Tongji University, Shanghai, China for kindly providing the $\beta$-arrestin 1 knockout mice, the $\beta$-arrestin 2 knockout mice, the $\beta 1 A R^{-/-} / \beta 2 A R^{-/-}$mice and $\beta$-arrestin $1 / 2$ antibodies. We also thank W. Kong at Peking University, Beijing, China for helpful discussions.

Funding This work was supported by grants from the National Key Basic Research Program of China (2013CB967700 to XY; 2012CB910402 to J-PS), the National Natural Science Foundation of China (31270857 to XY; 31100580 and 31271505 to J-PS; 81100455 to MC), the Shandong Natural Science Fund for Distinguished Young Scholars (JQ201320 to XY), the Fundamental Research Funds of Shandong University (2014JC029 to XY; 2012 TS114 to J-PS) and the Program for Changjiang Scholars and Innovative Research Team in University (IRT13028).

Contribution statement H-MW, J-HD and QL contributed to the study design, the acquisition, analysis and interpretation of data and drafting/ revising the article. QH, S-LN, WZ, MC, T-SC and XX contributed key experimental materials and contributed to the analysis of the data and revising the article. XY and J-PS contributed to the conception and design of the research, the analysis and interpretation of the data and to drafting/ revising the article. All authors approved the final version to be published. $\mathrm{XY}$ is responsible for the integrity of the work as a whole.

Duality of interest The authors declare that there is no duality of interest associated with this manuscript.

\section{References}

1. Hauge-Evans AC, King AJ, Carmignac D et al (2009) Somatostatin secreted by islet delta-cells fulfills multiple roles as a paracrine regulator of islet function. Diabetes 58:403-411

2. Hauge-Evans AC, Anderson RL, Persaud SJ, Jones PM (2012) Delta cell secretory responses to insulin secretagogues are not mediated indirectly by insulin. Diabetologia 55:1995-2004
3. Braun M, Ramracheya R, Amisten S et al (2009) Somatostatin release, electrical activity, membrane currents and exocytosis in human pancreatic delta cells. Diabetologia 52:1566-1578

4. Brunicardi FC, Kleinman R, Moldovan S et al (2001) Immunoneutralization of somatostatin, insulin, and glucagon causes alterations in islet cell secretion in the isolated perfused human pancreas. Pancreas 23:302-308

5. Hara MR, Kovacs JJ, Whalen EJ et al (2011) A stress response pathway regulates DNA damage through beta2-adrenoreceptors and beta-arrestin-1. Nature 477:349-353

6. Samols E, Weir GC (1979) Adrenergic modulation of pancreatic A, $\mathrm{B}$, and D cells alpha-adrenergic suppression and beta-adrenergic stimulation of somatostatin secretion, alpha-adrenergic stimulation of glucagon secretion in the perfused dog pancreas. J Clin Invest 63:230-238

7. Rizza RA, Cryer PE, Haymond MW, Gerich JE (1980) Adrenergic mechanisms for the effects of epinephrine on glucose production and clearance in man. J Clin Invest 65:682-689

8. Boden G, Master RW, Sattler MA, Martin JS, Tansy MF, Owen OE (1982) Adrenergic control of somatostatin release. Endocrinology 111:1166-1172

9. Samols E, Stagner JI, Weir GC (1981) Autonomic function and control of pancreatic somatostatin. Diabetologia 20(Suppl):388-392

10. Bernstein D, Fajardo G, Zhao M et al (2005) Differential cardioprotective/cardiotoxic effects mediated by betaadrenergic receptor subtypes. Am J Physiol Heart Circ Physiol 289:H2441-H2449

11. Dou HQ, Xu YF, Sun JP et al (2012) Thiopental-induced insulin secretion via activation of IP3-sensitive calcium stores in rat pancreatic beta-cells. Am J Physiol Cell Physiol 302:C796-C803

12. Olofsson CS, Salehi A, Holm C, Rorsman P (2004) Palmitate increases L-type $\mathrm{Ca} 2+$ currents and the size of the readily releasable granule pool in mouse pancreatic beta-cells. J Physiol 557:935-948

13. Rajagopal S, Ahn S, Rominger DH et al (2011) Quantifying ligand bias at seven-transmembrane receptors. Mol Pharmacol 80:367-377

14. Chung KY, Rasmussen SG, Liu T et al (2011) Conformational changes in the $\mathrm{G}$ protein $\mathrm{Gs}$ induced by the beta2 adrenergic receptor. Nature 477:611-615

15. Rasmussen SG, DeVree BT, Zou Y et al (2011) Crystal structure of the beta2 adrenergic receptor-Gs protein complex. Nature 477:549-555

16. Dong JH, Chen X, Cui M, Yu X, Pang Q, Sun JP (2012) beta2adrenergic receptor and astrocyte glucose metabolism. J Mol Neurosci 48:456-463

17. Nobles KN, Xiao K, Ahn S et al (2011) Distinct phosphorylation sites on the beta(2)-adrenergic receptor establish a barcode that encodes differential functions of beta-arrestin. Sci Signal 4:ra51

18. Morisco C, Condorelli G, Trimarco V et al (2005) Akt mediates the cross-talk between beta-adrenergic and insulin receptors in neonatal cardiomyocytes. Circ Res 96:180-188

19. Quoyer J, Longuet C, Broca C et al (2010) GLP-1 mediates antiapoptotic effect by phosphorylating Bad through a beta-arrestin 1-mediated ERK1/2 activation in pancreatic beta-cells. J Biol Chem 285:1989-2002

20. Vallejo M, Penchuk L, Habener JF (1992) Somatostatin gene upstream enhancer element activated by a protein complex consisting of CREB, Isl-1-like, and alpha-CBF-like transcription factors. J Biol Chem 267:12876-12884

21. Montminy M, Brindle P, Arias J, Ferreri K, Armstrong R (1996) Regulation of somatostatin gene transcription by cAMP. Adv Pharmacol 36:1-13

22. Andersen FG, Jensen J, Heller RS et al (1999) Pax6 and Pdx 1 form a functional complex on the rat somatostatin gene upstream enhancer. FEBS Lett 445:315-320

23. Montminy MR, Bilezikjian LM (1987) Binding of a nuclear protein to the cyclic-AMP response element of the somatostatin gene. Nature 328:175-178 
24. Bollheimer LC, Skelly RH, Chester MW, McGarry JD, Rhodes CJ (1998) Chronic exposure to free fatty acid reduces pancreatic beta cell insulin content by increasing basal insulin secretion that is not compensated for by a corresponding increase in proinsulin biosynthesis translation. J Clin Invest 101:1094-1101

25. Yamamoto KK, Gonzalez GA, Biggs WH 3rd, Montminy MR (1988) Phosphorylation-induced binding and transcriptional efficacy of nuclear factor CREB. Nature 334:494-498

26. Hagiwara M, Alberts A, Brindle P et al (1992) Transcriptional attenuation following cAMP induction requires PP-1-mediated dephosphorylation of CREB. Cell 70:105-113

27. Okamoto N, Nishimori Y, Nishimura T (2012) Conserved role for the Dachshund protein with Drosophila Pax6 homolog Eyeless in insulin expression. Proc Natl Acad Sci U S A 109:2406-2411

28. Ahlqvist E, Turrini F, Lang ST et al (2012) A common variant upstream of the PAX6 gene influences islet function in man. Diabetologia 55:94-104

29. Hart AW, Mella S, Mendrychowski J, van Heyningen V, Kleinjan DA (2013) The developmental regulator Pax6 is essential for maintenance of islet cell function in the adult mouse pancreas. PLoS One 8:e54173

30. Sander M, Neubuser A, Kalamaras J, Ee HC, Martin GR, German MS (1997) Genetic analysis reveals that PAX6 is required for normal transcription of pancreatic hormone genes and islet development. Genes Dev 11:1662-1673

31. Mikkola I, Bruun JA, Bjorkoy G, Holm T, Johansen T (1999) Phosphorylation of the transactivation domain of Pax6 by extracellular signal-regulated kinase and p38 mitogen-activated protein kinase. J Biol Chem 274:15115-15126

32. Reiter E, Ahn S, Shukla AK, Lefkowitz RJ (2012) Molecular mechanism of beta-arrestin-biased agonism at seven-transmembrane receptors. Annu Rev Pharmacol Toxicol 52:179-197

33. Shenoy SK, Lefkowitz RJ (2011) beta-Arrestin-mediated receptor trafficking and signal transduction. Trends Pharmacol Sci 32:521-533

34. Xiao K, Sun J, Kim J et al (2010) Global phosphorylation analysis of beta-arrestin-mediated signaling downstream of a seven transmembrane receptor (7TMR). Proc Natl Acad Sci U S A 107:15299-15304

35. Buelli S, Rosano L, Gagliardini E et al (2013) beta-Arrestin-1 drives endothelin-1-mediated podocyte activation and sustains renal injury. J Am Soc Nephrol 25:523-533

36. Kong KC, Butcher AJ, McWilliams P et al (2010) M3-muscarinic receptor promotes insulin release via receptor phosphorylation/ arrestin-dependent activation of protein kinase D1. Proc Natl Acad Sci U S A 107:21181-21186 